\title{
The Role of Laparoscopy in Management of Congenital Anomalies of the Müllerian System: Literature Review and Case Series
}

\author{
Ettedal A. Aljahdali, MBBCH, SBOG, CBG OBGYN AFSA \\ Department of Obstetrics and Gynecology, Faculty of Medicine \\ King Abdulaziz University, Jeddah, Saudi Arabia
}

\section{Correspondence \\ Dr. Ettedal A. Aljahdali \\ P.O. Box 80215, Jeddah 21589, Saudi Arabia \\ e.M:dr.aljahdali@hotmail.com \\ Submission: 17 Dec. 2014 \\ Accepted: 9 Feb. 2015}

\section{Citation}

Aljahdali EA. The role of laparoscopy in management of congenital anomalies of the Müllerian system: Literature review and case series. JKAU Med Sci 2015; 22 (2): 39-46. DOl: 10.4197/Med. 22.2.6

\begin{abstract}
Structural defects of the female reproductive tract become apparent at varying chronologic times during intrauterine life. The diagnosis of all female reproductive tract abnormalities has benefited from enhancements in imaging techniques and the surgical treatment thereof has improved due to advances in the techniques and instrumentation of both surgical and non-surgical procedures. In the last decade, laparoscopy has become increasingly popular and has successfully replaced several open surgical procedures. It has been applied to many aspects of gynecological surgery and has become the procedure of choice for gynecological surgery. A review of the recent literature continues to support the utilization of laparoscopy for the management of genital tract malformation. This review aims to appraise the recent literature to determine how laparoscopy may aid in the diagnosis of reproductive tract anomalies and their treatment, its success in replacing the open surgery in some cases, and the presentation of some cases that were successfully diagnosed and treated with laparoscopy.
\end{abstract}

\section{Keywords}

Laparoscopy; Müllerian system anomalies; Literature Review

\section{Introduction}

ongenital abnormalities of the Müllerian ducts often escape diagnosis for a long period of time due to a lack of symptoms. Despite this asymptomatic nature, these abnormalities may negatively impact a woman's health, both obstetric and gynecological ${ }^{[1]}$.

The management of all female reproductive tract anomalies has seen dramatic improvement resulting from enhancements in the imaging techniques used for diagnosis, in addition to advances in the techniques and instrumentation used for both surgical and nonsurgical procedures ${ }^{[2]}$.

In the last decade, laparoscopy has become very popular and has successfully replaced several open surgical procedures. It has been applied to many aspects of gynecological surgery, including accurate diagnosis and treatment of anomalies. In addition, laparoscopy offers the critical benefit of preventing or reducing adhesions, which makes it the procedure of choice for gynecological surgery ${ }^{[3,4]}$. 
Due to the, usually, asymptomatic nature, and the resulting low rate of diagnosis, it is difficult to accurately evaluate the incidence of congenital uterine anomalies. However, the current best estimates indicate approximately $4.3 \%$ of fertile women, $3.5 \%$ of infertile women, and $13 \%$ of women with recurrent pregnancy loss suffer these abnormalities ${ }^{[5]}$.

One well-designed study evaluated the uteri of 679 women who had experienced normal reproductive outcomes with laparoscopy or laparotomy before tubal ligation, and hysterosalpingogram five months after sterilization ${ }^{[6]}$. The prevalence of abnormalities was estimated to be $3.2 \%$ in total, with septate uteri comprising $90 \%$, bicornuate uteri $5 \%$, and didelphic uteri $5 \%{ }^{[5-7]}$. Other studies of congenital anomalies of the Müllerian system in general (including uterus, vagina, cervix, tubes) estimate between $0.1 \%$ and $1.5 \%$ of women in the general population are affected, with $90 \%$ of these anomalies mainly affecting the uterus.

These anomalies are often only discovered incidentally, or during the investigation of infertility, or following repeated fetal loss. Laparoscopy has become the primary choice for accurately diagnosing and successfully treating uterovaginal abnormalities because it provides a superior visual field, including of the pelvic structures, a good monitor for endometriosis and hysteroscopic procedures, replace absent vagina, resects abnormal Müllerian structures with the benefit of shorter recovery time, and reduced postoperative adhesion and pain ${ }^{[4]}$.

This review aims to appraise the recent literature to determine how laparoscopy may aid in the diagnosis of reproductive tract anomalies and their treatment, its success in replacing the open surgery in some cases, and the presentation of some cases that were successfully diagnosed and treated with laparoscopy.

\section{The Literature Review}

The search was done for genital tract anomalies and laparoscopy between 1990-2014, including case reports, reviews, and articles. The reference lists of the identified articles were searched for further relevant articles. A textbook was reviewed for basic science and understanding of anatomy.

\section{Emryology}

Multiple overlapping steps are required for normal growth of the female genital tract; beginning three weeks after conception and continuing into the second trimester of pregnancy. Primordial germ cells migrate to the genital ridge to begin the development of the gonads, the type of which is governed by the chromosomal sex. An absence of Sertoli cells 6 to 7 weeks after conception indicates ovarian differentiation and after 13.5 weeks the ovarian primordial follicles will be identifiable ${ }^{[8]}$. The Müllerian ducts can be identified around the sixth week of development. The fusion of the caudal part of the Müllerian ducts forms the uterovaginal canal near the $12^{\text {th }}$ week of gestation, which then inserts itself into the dorsal wall of the urogenital sinus at Müller's tubercle. Cranial unfused parts form the fimbria and fallopian tubes, while the caudal, fused parts form the uterus and upper two thirds of the vagina. The sinovaginal bulbs are two solid cords of tissues in the urogenital sinus at the distal aspect of the Müllerian tubercle. The sinovaginal bulbs proliferate into the caudal end of the uterovaginal canal to form a solid vaginal plate, which will be canalized after the degeneration of the central cells to form the vaginal lumen; this process is normally complete by the $20^{\text {th }}$ week. The vaginal lumen is separated from the urogenital sinus by the hymenal membrane which usually ruptures before birth due to degeneration of the central epithelial cells. However, a thin fold of mucous membrane persists around the vaginal introitus ${ }^{[9]}$.

\section{Classification}

A classification system is a trial to arrange the disorders into groups based on symptomatology, treatment, or prognosis. Unfortunately, Müllerian defects have yet to be classified into a universally accepted and interpreted system ${ }^{[9]}$.

The American Fertility Society in 1988 produced a standard form for classification of Müllerian defects.

Type I: Müllerian agenesis or hypoplasia.

Type II: Unicornuate uterus.

Type III: Uterus didelphys.

Type IV: Uterus bicornuate.

Type V: Septate Uterus.

Type VI: Diethylstilbestrol related anomalies.

This descriptive classification concentrates mainly on defects of vertical fusion and dysgenesis of the uterus. Consideration must also be given to related abnormalities in the vagina, cervix, fallopian tubes, and renal system ${ }^{[9]}$. 


\section{Developmental Defects}

When considering the Müllerian system three common developmental abnormalities are encountered:

- Agenesis

- Lateral fusion defects

- Vertical fusion defects

+Diethylstilbestrol induced defects, and hymenal anomalies.

\section{Agenesis}

The Mayer-Rokitansky-Küster-Hauser syndrome refers to a congenital absence of the vagina in addition to variable uterine development, which results from Müllerian agenesis. Different types of uterine development may result in lateral hemi-uteri or uterine horns, a midline uterus sans cervix, or complete absence of uterine structures.

\section{Lateral Fusion Defects}

The most common kind of Müllerian abnormality are lateral fusion defects. The Müllerian anomalies are symmetric or asymmetric, obstructed or nonobstructed. A septum is the most common type of anomaly, which will cause septate or arcuate uterus, unicornuate uterus, bicornuate uterus and uterine didelphys.

\section{Vertical Fusion Defects}

Vertical fusion defects are due to either defective fusion or canalization. This results in obstructed or nonobstructed anomalies, and occurs in approximately 1 in 30,000 to 1 in 80,000 women $^{[10]}$. These septa may be found at different positions within the vagina: roughly 46 percent located in the upper portion; 35-40 percent in the central portion; $15-20$ percent in the lower portion $^{[11]}$. The thickness of these septa is generally less than 1 centimeter, and the septa may display a small central or eccentric perforation.

\section{Diethylstilbestrol Induced Defects}

Exposure to diethylstilbestrol (DES), a synthesized estrogen administered between 1949 and 1971, is associated with a variety of female genital tract abnormalities.

\section{Etiology}

The underlying etiology of congenital Müllerian defects is poorly understood. The karyotype of women with these anomalies is usually normal (46, XX in 92 percent). Most of the defects are likely to be related to polygenic and multifactorial causes.

\section{Clinical Manifestations}

Congenital anomalies of the Müllerian duct are often diagnosed incidentally during the evaluation of gynecologic and obstetric problems, after hysterosalpingography during a work-up of infertility or reproductive loss. The associated signs and symptoms vary depending upon the defect involved:

- Adolescents may experience increased pain of the pelvis (either cyclic or noncyclic), dysmenorrhea, abnormal vaginal bleeding, or vaginal pain.

- Menstrual abnormalities: Hypomenorrhea may result from minimal endometrium; amenorrhea may be a sign of Mayer-Rokitansky-Küster-Hauser syndrome or a vertical fusion defect.

- Longitudinal vaginal septum may occur alone, but is usually seen with didelphic or other forms of double uterus. A vaginal septum may lead to dyspareunia or bleeding despite the application of a tampon, leukorrhea, or dystocia at delivery.

- If one side of the vagina is obstructed, complications such a hydrocolpos and hematocolpos may occur and a mass may be detected on bimanual examination. In addition, microperforations into the obstructed vagina can lead to infection.

- The woman may present with endometriosis and its associated symptoms if a non-communicating functioning horn seeds the peritoneum through retrograde menstruation.

- Obstetrical complications are more common with Müllerian anomalies. These include an increased risk of miscarriage, prematurity, intrauterine growth restriction, antepartum and postpartum bleeding, cervical incompetence, abnormal fetal presentation, pregnancy-associated hypertension, and cesarean delivery. Uteroplacental insufficiency may result from a restriction of growth, which in turn may be related to a small uterine cavity or insufficient vascularization of the uterus ${ }^{[5]}$. 


\section{Diagnosis}

Diagnosis of a structural abnormality may often be defined by hysterosalpingography performed during an evaluation of fertility, or by ultrasonography performed to evaluate a pain or mass of the pelvis. Yet, definitive diagnosis often requires other studies. The "gold standard" for diagnosing reproductive tract abnormalities is magnetic resonance imaging $(\mathrm{MRI})^{[12,13]}$. However, the normal, unestrogenized, prepubescent uterus is small and would be difficult to image even with MRI. Magnetic resonance imaging is very useful in determining the presence or absence of a cervix in a complex anomaly, or the presence of functioning endometrium in the event of a noncommunicating obstructed rudimentary uterine horn. Magnetic resonance imaging may be unable to identify a rudimentary uterine horn located laterally along the psoas muscle and pelvic sidewall ${ }^{[14]}$.

Endovaginal ultrasound, sonohysterography and 3-dimensional (3-D) ultrasound are noninvasive, highly accurate modalities that can be used for evaluation, and yield detailed images of the uterine anatomy, so are recommended to be utilized for initial imaging due to the lower cost vs. MRI, which can then be used for further evaluation ${ }^{[15-17]}$.

\section{Role of Lararoscopy in Diagnosing and Treating Müllerian Anomalies}

Gynecological surgery is currently trending toward procedures of minimal invasion; seen as a better overall alternative than traditional gynecological surgery. Laparoscopy provides a superior visual field, including of the pelvic structures, and with reduced adhesion. Reviewing literature on laparoscopy and genital tract anomalies showed case series of patients diagnosed and treated successfully by laparoscopy or vaginally assisted laparoscopy.

In a case study published in 2007, a series of 15 patients displaying a non-communicating Müllerian system (between 1999 and 2005), were treated by laparoscopy to remove the obstructed horn. The study concluded that laparoscopy is suitable for removing obstructions of the Müllerian system. However, it must be emphasized that such operations remain major endeavors, and require a pediatric gynecologist's involvement as well as a laparoscopic surgeon's ${ }^{[18]}$. Another similar study, published in 1999 regarding the same type of cases, considered minimally invasive surgery as accepted practice with the advantage of smaller incisions and better visualization, and reduced postoperative pain, adhesions, and hospital stay ${ }^{[19]}$. Laparoscopy can be used to treat endometriosis or endometriotic cysts with the associated adhesions performed in the same setting. Laparoscopy can also be utilized in the diagnosis and treatment of patients with abnormal sexual conditions, such as the laparoscopy-assisted hysterectomy of a male with pseudohermaphroditism and persistent Müllerian duct derivatives that was first reported in $1997^{[20]}$.

In good, expert hands Laparoscopic gonadectomy and vaginoplasty in androgen insensitivity syndrome has proven that laparoscopy is the best option for the patients. A study from Taiwan reviewed 18 patients presenting a congenital absence of the vagina who were treated by laparoscopic neovaginoplasty (from 1992 to 1994): all had positive outcome with reduced hospital stay, better cosmetics, less emotional stress, and a decreased risk of adhesions and dyspareunia[21]. Another case report from the same center was published in 1999 of a 12 year-old girl with congenital agenesis of the vagina and uterine cervix who received a full thickness skin graft reconstruction assisted by laparoscopy with successful result and normal regular menstruation at one year follow-up ${ }^{[22]}$.

Another study was conducted in Genève and Italy on laparoscopic vaginal reconstruction (Davydov maneuver) for the treatment of vaginal agenesis and its effect on sexual life. In this laparoscopic approach a purse-string suture technique was employed to close the abdominal end of the neovagina. In the study, 27 of 324 women who underwent this procedure had laparoscopically-assisted surgery. The success rates were similar for both the laparoscopically-assisted and traditional approaches; however, the laparoscopically assisted operation resulted in shorter operating times, lower intraoperative complications, shorter hospital stays, and no external scars. Postoperatively, sexual function approached that of matched controls without gynecological disorders ${ }^{[8,23]}$.

Previously, uterine cervical agenesis was treated by hysterectomy because complications after cervical recanalization were common and a viable pregnancy was improbable. Recent progress in the technology for reproductive assistance and advancements in laparoscopic surgical techniques suggest that conservative surgery is a viable option and should perhaps be considered for first-line treatment. A case report from Hôpital Tenon AP-HP de Paris FRANCE in 2009 confirmed the feasibility of laparoscopicassisted treatment of cervical atresia with vaginal 
aplasia without fundal incision to decrease the risk of intrauterine adhesions and uterine rupture during pregnancy, even if cesarean section is recommended in this specific setting ${ }^{[24]}$. The largest study to date to examine outcomes after open uterovaginal anastomosis found that only $22 \%$ of the 18 patients required additional surgery. Furthermore, the investigators reported six unassisted pregnancies in four of these patients. Despite these positive results, the risk of sepsis and death remain present, as reported in one case, resulting from escalating infection ${ }^{[25-27]}$.

Hysteroscopic surgery represents the primary choice for the treatment of septate uterus but does not make full knowledge available regarding the external morphology of the uterus. Concomitant use of laparoscopy for a patient undergoing hysteroscopy can distinguish between a septate and a bicornuate uterus and help to guide operative hysteroscopy; it can also reflect the light of the hesteroscope approaching the fundus so perforation can be avoided. Also, thermal injury to the bowels and other adjacent organs can be avoided or diagnosed immediately ${ }^{[28]}$.

The experience at King Abdulaziz University Hospital (KAUH) found that laparoscopy and laparoscopic assisted procedures also have a major rule in diagnosing and managing Müllerian duct abnormalities and intersex cases. Here we will present some of the cases that have been done in $\mathrm{KAUH}$.

The first case is a 20 year-old female presenting with primary amenorrhea, diagnosed to have complete Müllerian agenesis; colon vaginoplasty was performed for her by laparotomy. At the same time her younger sister, 18 years-old, was also found to have the same problem, but she had the chance to have laparoscopic assisted segmoid colon vaginoplasty. In Figure 1 the black arrow (1) shows the re-anastomosis of the rectum with the sigmoid colon after the isolation of 10 $\mathrm{cm}$ part of the sigmoid with its blood supply as a new vagina, while the red arrow (2) shows the new vagina after anastomosis with the vaginal vault. Figure 2 also shows the same but with the part of the peritoneum with the blood supply more clearly, indicated by the blue arrow (3).

In the second patient laparoscopy was found to be very helpful in the diagnosis and management at the same time, as we can see in Figures 3-5. This patient had rudimentary uterus, Rt ovary and Lt testes, so left side gonadectomy was performed.

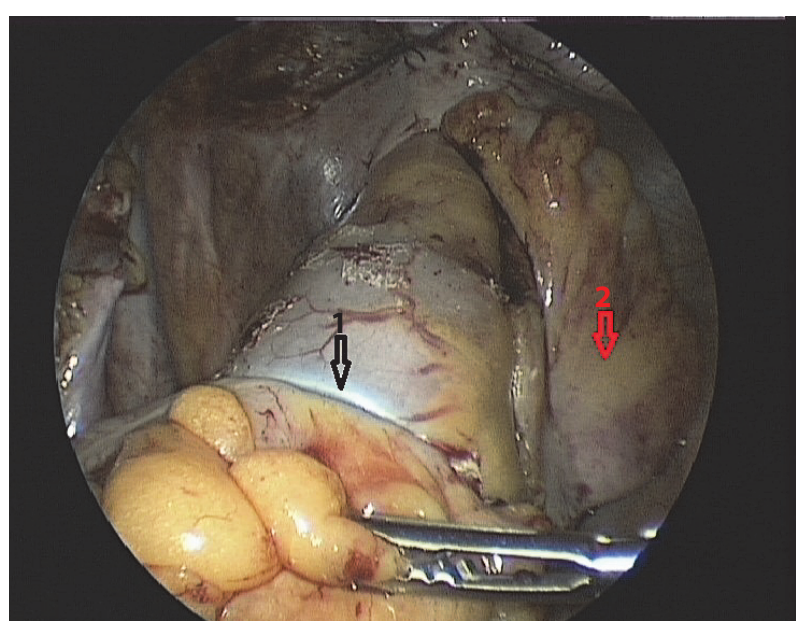

Figure 1. Reanastomosis point (black arrow) of colon after resection of $10 \mathrm{~cm}$ part as new vagina (red arrow).

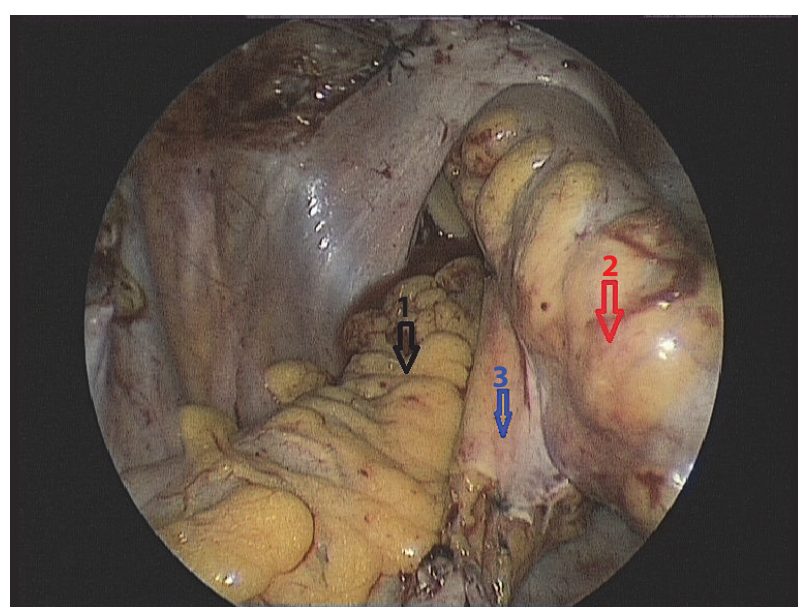

Figure 2. Colon (black arrow), new vagina (red arrow) after reanastomsis with the lower vaginal vault, the peritoneal part with its blood supply (blue arrow)

Other patient with chronic lower abdominal pain which was diagnosed as two uterine horns with lower vaginal atresia bilateral hematometria hematocolpos vaginovesical fistula and was menstruating monthly through the urethra. Figures 6 and 7 show a patient with obstructed uterine horn and extensive adhesions. After the release of adhesions and vaginoplasty she is now having a normal sexual life and normal menstruation, with less pain than before.

\section{Conclusions}

The review of the literature and our experience in $\mathrm{KAUH}$ continues to support the use of laparoscopy as 


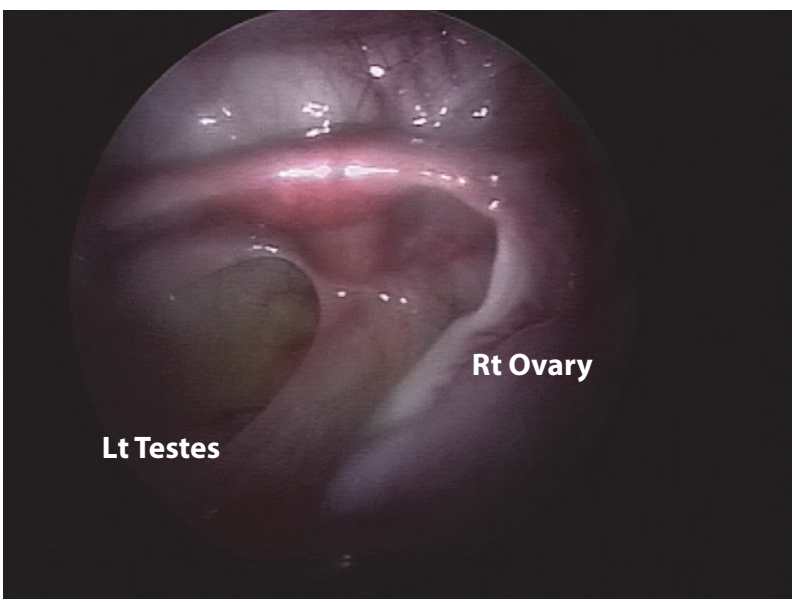

Figure 3. Rudimentary uterus, Rt ovary and Lt testes.

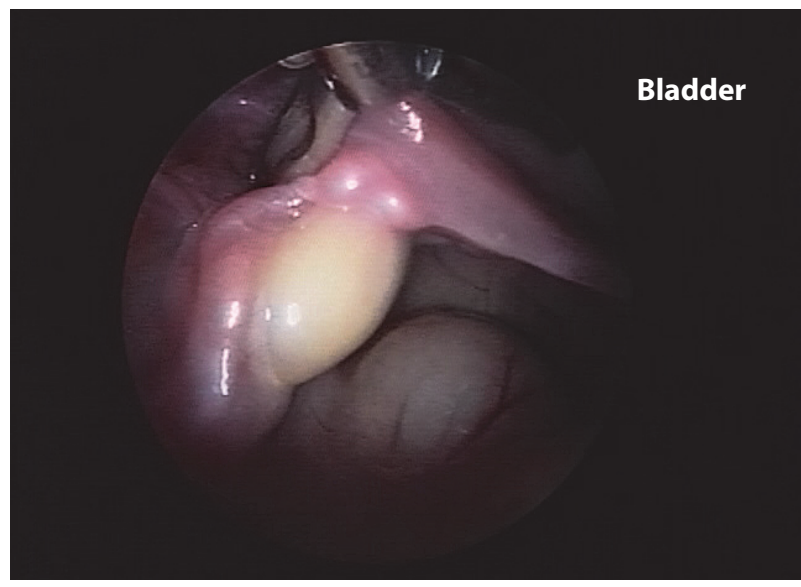

Figure 4. Lt testes.

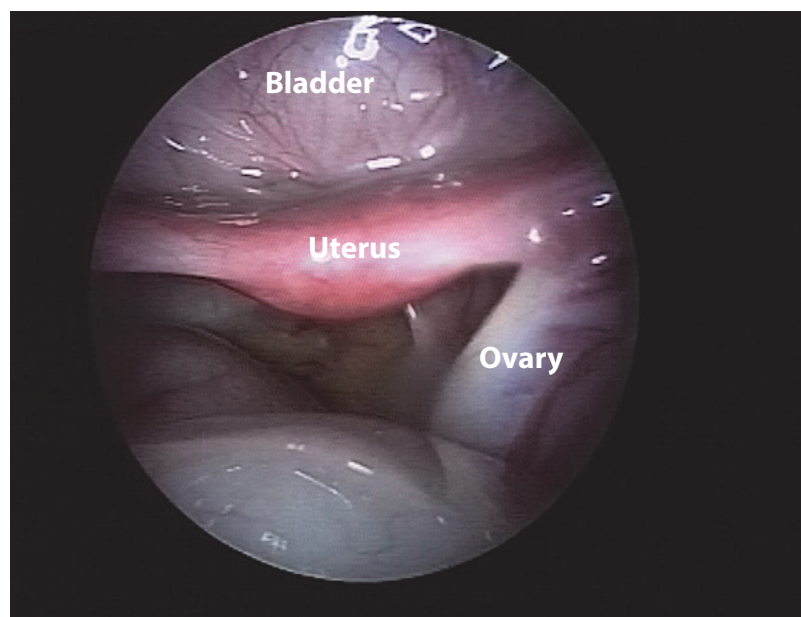

Figure 5. Rudimentary uterus, Rt ovary and Lt testes.

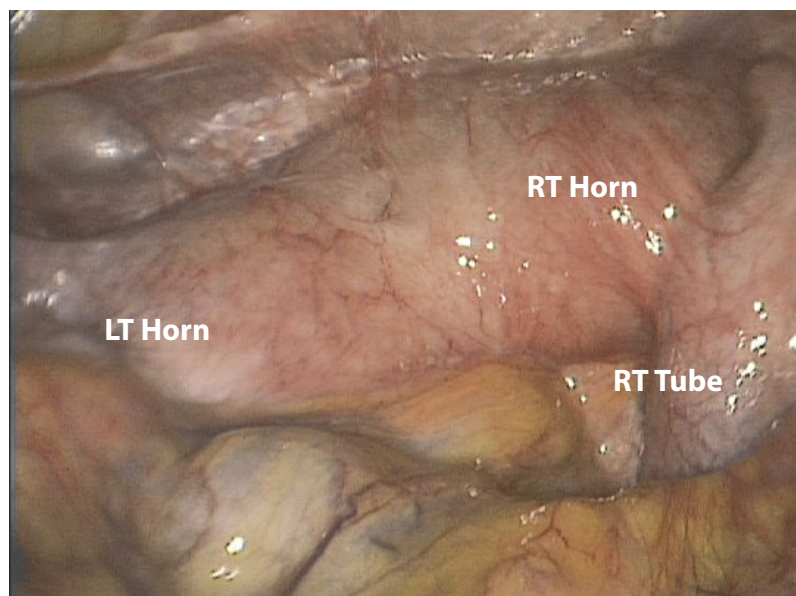

Figure 6. Obstructed uterine horn and extensive adhesions.

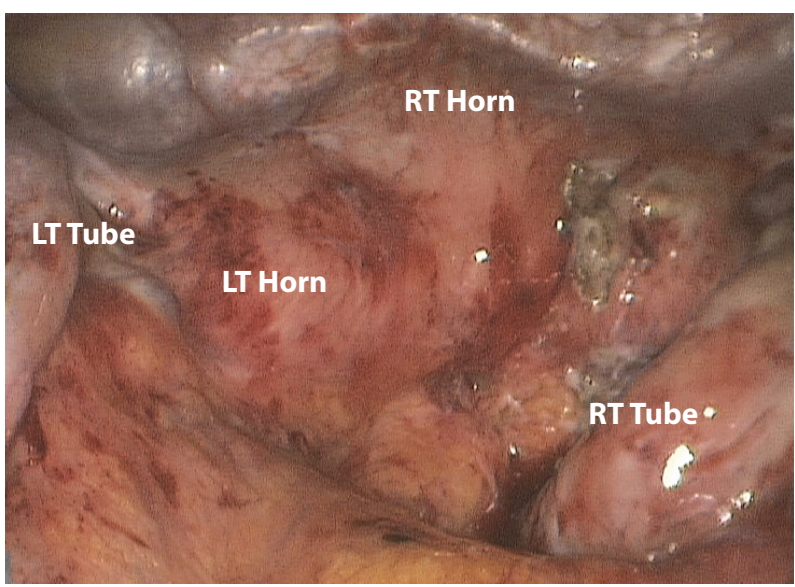

Figure 7. Obstructed uterine horn and extensive adhesions.

an important tool for diagnosing and treating genital tract anomalies and offers promising results both in the immediate post-op period and over time. It is well accepted as a minimally invasive surgery with smaller incisions and better visualization, reduced postoperative pain, adhesions, and hospital stay.

\section{Conflict of Interest}

The author has no conflict of interest.

\section{Disclosure}

The author did not received any type of commercial support either in forms of compensation or financial for this study. The author have no financial interest in any of the products or devices, or drugs mentioned in this article. 


\section{Ethical Approval}

Obtained.

\section{References}

[1] Grimbizis GF, Gordts S, Di Spiezio Sardo A, Brucker S, De Angelis C, Gergolet M, Li TC, Tanos V, Brölmann H, Gianaroli L, Campo R. The ESHRE/ESGE consensus on the classification of female genital tract congenital anomalies. Hum Reprod 2013; 28(8): 2032-2044.

[2] Laufer MR. Structural abnormalities of the female reproductive tract. In: Pediatric and Adolescent Gynecology. 6th ed, 2012. Chptr 12, 188.

[3] Gomel V. Laparoscopy. Can Med Assoc J 1974; 111 (2): 167 169.

[4] Bailez MM. Laparoscopy in uterovaginal anomalies. Semin Pediatric Surgery 2007; 16(4): 278-287.

[5] Grimbizis GF, Camus M, Tariatzis BC, Bontis JN, Devroey P. Clinical implications of uterine malformations and hysteroscopic treatment results. Hum Reprod Update 2001; 7(2): 161-174.

[6] Simón C, Martinez L, Pardo F, Tortajada M, Pellicer A. Müllerian defects in women with normal reproductive outcome. Fertile Steril 1991; 56(6): 1192-1193.

[7] Jurkovic D, Grboeck K, Tailor A, Nicolaides KH. Ultrasound screening for congenital uterine anomalies. J Obstet Gynaecol 1997; 104(11): 1320-1321.

[8] Voutilainen R. Differentiation of the fetal gonads. Horm Res 1992; 38 Suppl 2: 66-71.

[9] [No authors listed]. The American Fertility Society classifications of adnexal adhesions, distaltubal occlusion, tubal occlusion secondary to tubal ligation, tubal pregnancies, mullerian anomalies and intrauterine adhesions. Fertil Steril 1988; 49(6): 944-955.

[10] Rock JA, Azziz R. Genital anomalies in childhood. Clin Obstet Gynecol 1987; 30(3): 682-696.

[11] LODI A. [Clinical and statistical study on vaginal malformations at the Obstetrical and Gynecological Clinic in Milano, 1906-50.]. Ann Ostet Ginecol 1951; 73(9): 12461285.

[12] Markham SM, Parmley TH, Murphy AA, Huggins GR, Rock JA. Cervical agenesis combined with vaginal agenesis diagnosis by magnetic resonance imaging. Fertil Steril 1987; 48(1): 143-145.

[13] Bakri YN, al-Sugair A, Hugosson C. Bicornute nonfused rudimentary uterine horns with functioning endometrial and complete cervical- vaginal agenesis: magnetic resonance diagnosis. Fertil Steril 1992; 58(3): 620-621.

[14] Economy KE, Barnewolt C, Laufer MR. A comparison of MRI and laparoscopy in detecting pelvic structures in cases of vaginal agenesis. J Pediatr Adolesc Gyencol 2002; 15(2): 101-104.
[15] Pellerito JS, MCCarthy SM, Doyle MB, Glickman MG DeCherney AH. Diagnosis of uterine anomalies: relative accuracy of MR imaging, endovaginal sonography, and hysterosalpingography. Radiology 1992; 183(3): 795-800.

[16] Bakri YN, al-Sugair A, Hugosson C. Bicornuate nonfused rudimentary uterine horns with functioning endometria and complete cervical-vaginal agenesis: magnetic resonance diagnosis. Fertil Steril 1992; 58(3): 620-621.

[17] Economy KE, Barnewolt C, Laufer MR. A comparison of MRI and laparoscopy in detecting pelvic structures in cases of vaginal agenesis. J Pediatr Adolesc Gynecol 2002; 15(2): 101-104.

[18] Strawbridge LC, Crouch, Cutner AS, Creighton SM. Obstructive mullerian anomalies and modern laparoscopic management. J Pediatr Adolesc Gynecol 2007; 20(3): $195-$ 200.

[19] Nezhat CR, Smith KS. Laparoscopic management of a unicornuate uterus with two cavitated, noncommunicating rudimentary horns: case report. Human Reprod 1999; 14(8): 1965-1968.

[20] Colacurci N, Cardone A, De Franciscis P, Landolfi E, Venditto $\mathrm{T}$, Sinisi AA. Laparoscopic hysterectomy in a case of male pseudohermaphroditism with persistent Müllerian duct derivatives. Human Reprod 1997; 12(2): 272-274.

[21] Soong YK, Chang FH, Lai YM, Lee CL, Chou HH. Results of modified laparoscopically assisted neovaginoplasty in 18 patients with congenital absence of vagina. Human Reprod 1996; 11(1): 200-203.

[22] Lee $C L$, Wang $C$, Liu $Y H$, Yen $C F$, Lai $Y L$, Soong $Y K$. Laparoscopically assisted full skin graft for reconstruction in congenital agenesis of vagina and uterine cervix, case report. Human Reprod 1999; 14(4): 928-930.

[23] Lee $C L$, Wang $C J$, Yen $C F$, Mu WC, Jain S, Soong YK. Uterovaginal canalization and endometrial ablation of the obstructed uterine horn with hypoplastic cervix in the didelphic uterus. J Am Assoc Gynecol Laparosc 2001; 8(1): 151-153.

[24] Daraï E, Ballester M, Bazot M, Paniel BJ. Laparoscopicassisted uterovaginal anastomosis for uterine cervix atresia with partial vaginal aplasia, case report. J Minim Invasive Gynecol 2009; 16(1): 92-94.

[25] Creighton SM, Davies MC, Cutner A. Laparoscopic management of cervical agenesis. Fertil Steril 2006; 85(5): 1510.e13-15.

[26] Deffarges JV, Haddad B, Musset R, Paniel BJ. Utero-vaginal anastomosis in women with uterine cervix atresia: longterm follow-up and reproductive performance. A study of 18 cases. Hum Reprod 2001; 16(8): 1722-1725.

[27] Casey AC, Laufer MR. Cervical agenesis: septic death after surgery. Obstet Gynecol 1997; 90(4 Pt 2): 706-707.

[28] Zabak K, Bénifla JL, Uzan S. [Septate uterus and reproduction disorders: current results of hysteroscopic septoplasty]. Gynécol Obstét Fertil 2001; 29(11): 829-840. 


\title{
دور جراحة المناظير في تثخيص وعلاج تشوهات الجهاز التناسلي الأنثوي مراجعة للكتابات الحديثة وتقديم بعض الحالات
}

\author{
| اعتدال عطية الجحدلي

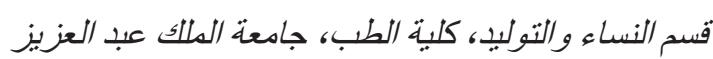 \\ جذة ـ المدلكة العربية السعودية النعاهية
}

المستخلص. تظهر أعر اض التشوهات الخلقية في الجهاز التناسلي الأنثوي في مر احل مختلفة من حياة الأنثى. وقد تطورت تكنولوجيا التشخيص الإشعاعي و المناظير الجر احية مما ساعد في تثخيص هذه النتوهات بشكل افضل. وفي العقد الأخير

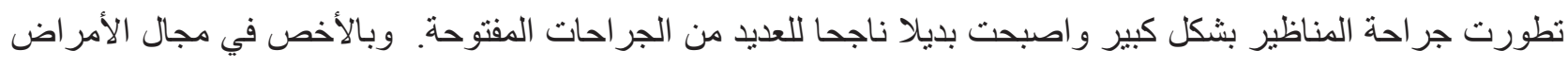

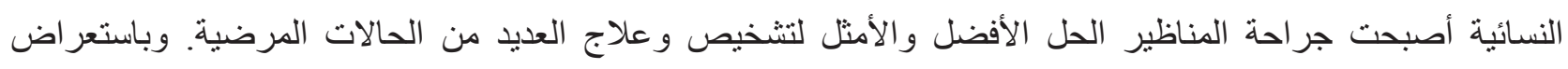

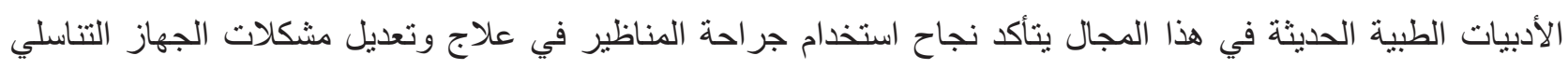

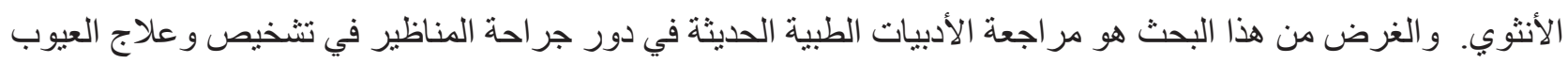

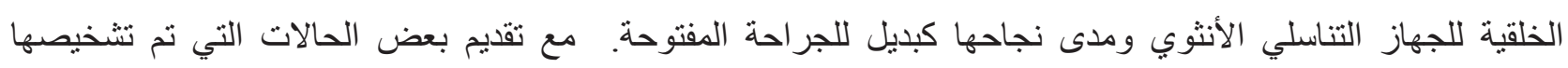
و علاجها بالمنظار الجراحي. 